\title{
Gustavo Meza: Premio Nacional de Arte en Chile
}

Chile viene reconociendo a sus valores en el campo del arte desde la década de los años 40. En efecto, varias personalidades del mundo del teatro han recibido el Premio Nacional de Arte en Teatro, tales como Don Pedro de la Barra, Agustín Siré, María Cánepa, Pedro Mortheiru, Ana González, Bélgica Castro, Fernando González, entre otros.

El año pasado este premio fue asignado a Gustavo Adolfo Meza Wevar (Osorno, 1936), conocido pedagogo y director teatral. Realizó estudios de Psicología y Dirección Teatral en la Universidad de Chile desde 1954 hasta 1957. Pero al ver Fuenteovejuna - dirigida magistralmente por quien sería su maestro de Dirección Teatral, Don Pedro Orthous - por el Teatro Experimental de la Universidad de Chile descubrió que el teatro era su vocación. Su carrera profesional comenzó en 1958 al ser invitado por el Teatro de la Universidad de Concepción a dirigir Dos + dos $=$ cinco de Isidora Aguirre. Inmediatamente es contratado como director artístico en dicha compañía y más tarde como profesor de Actuación en la Escuela de Teatro de esa misma universidad.

En 1964 retorna a la capital en donde se desempeña como director escénico de varias compañías tales como Ictus, Teatro del Angel, Compañía de los Cuatro, El Cabildo, etc. En esa época dirige además, el Taller de Teatro de la Casa de la Cultura de Ñuñoa, y da clases de Actuación en la Academia del Teatro de Ensayo de la Universidad Católica de Santiago y desde 1967 en la Escuela de Teatro de la Universidad de Chile. En 1968 dirige el Taller de Experimentación Teatral de la UC donde monta Nos tomamos la universidad de Sergio Vodanovic (Premio de la Crítica 1969).

A principios de la década de los 70 asesora el grupo de teatro de la Universidad del Norte (Antofagasta) en el montaje de Nos tomamos la universidad la cual participa en el Tercer Festival de Teatro Universitario de Manizales, Colombia, donde toma contacto con Jerzy Grotowski y Enrique Buenaventura. Para el elenco de la Universidad Católica de Santiago dirige Almas Perdidas de Antonio Acevedo Hernández. 
Después del golpe de estado dirigido por Pinochet, tanto la escuela como la compañía profesional de la U. de Chile son totalmente desmanteladas. En ese entonces Meza funda el Teatro Imagen junto a Yael Unger, y Tennyson Ferrada, habiendo estrenado El día que soltaron a Joss de Hugo Klaus (Premio de la Crítica 1974). Después vinieron Mi adorada idiota de Francois Boyer (Premio Chilena Consolidada); Topaze de Marcel Pagnol, El visitante y Abraham

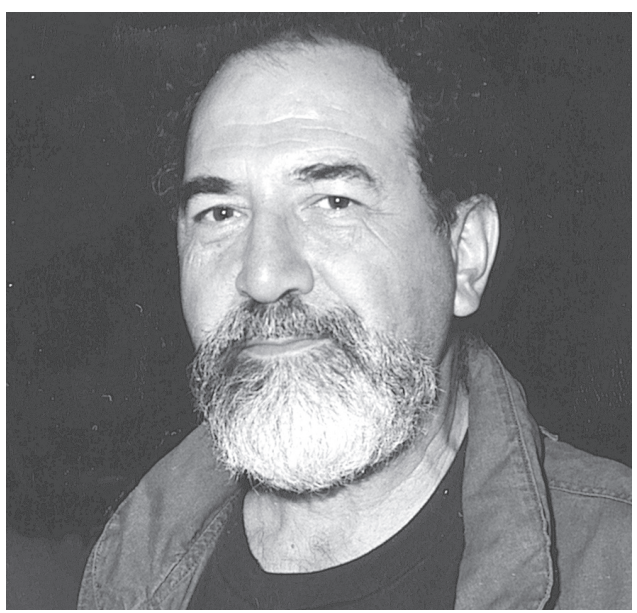

Foto: Consejo Nacional de Cultura, Chile

y Samuel de Victor Haim, Te llamabas Rosicler de Luis Rivano (Premio Molière), Las 3000 palomas y el Loro (de Meza y Andrés Pizarro); Lo crudo, lo cocido y lo podrido del entonces debutante Marco Antonio de la Parra, y que aunque previamente fuera prohibida por las autoridades de la Universidad Católica, obtiene los premios de la Crítica, de los Cronistas de Espectáculos y el Festival TOLA (Theater of Latin America en Estados Unidos); ¡Viva Zomoza!, con textos de Meza mezclados con los de Juan Radrigán. Como dramaturgo, Meza se hizo conocido con El último tren, el cual ganó los premios de la Crítica y de la Asociación de Periodistas de Espectáculos (APES).

La actriz Ana González lo invita a dirigir Las muertes de Sabina, texto de Juan Radrigán que obtiene un tremendo éxito que consagra al casi entonces desconocido autor. Después dirige para su grupo obras como Macías de Sergio Marras; La Meka de Enrique Lihn; Los inconvenientes de poner fábricas de alimentos en barrios residenciales de Pablo de Carolis.

En los años 80 Meza es invitado a formar parte de la Comisión de Derechos Humanos de Chile e informa sobre la situación de la cultura ante las Naciones Unidas en Nueva York. Igualmente es elegido Secretario General del ITI - Chile. También fue uno de los creadores de la Sociedad de Autores Nacionales de Teatro, Cine y TV. Igualmente es invitado a formar parte del consejo del Festival Internacional de Teatro Santiago a Mil. Organiza el Primer Festival Juvenil-Obrero de Teatro con el auspicio de la Confederación de Panificadores, Confederación Ranquil, Centro Cultural Escandinavo y 
Teatro Imagen. Y sigue dirigiendo: para el grupo Teknos (perteneciente a la Universidad Técnica del Estado) monta La Fierecilla Domada de Shakespeare en versión de Soto Ramos y La Viudad Astuta de Goldoni.

En esa década viaja a la isla de Chiloé invitado por el Arzobispado de Ancud a participar en sus Jornadas Culturales en oposición al llamado Proyecto Astillas del Gobierno de Pinochet que pretendía vender las maderas de esa isla al Japón.

En 1984 se establece - con el estreno de Cartas de Jenny de Gustavo Meza -, el local del Teatro y Escuela Imagen en la calle Loreto 400 en el Barrio Bellavista de Santiago. Con dicha obra participa en festivales en Paraguay, Uruguay, Venezuela, Colombia, México (donde obtiene el Premio Gorostiza), España y Estados Unidos.

Entre las distinciones que ha recibido podemos mencionar la medalla Pedro de la Barra a su trayectoria otorgada por el Rector de la Universidad de Chile; el premio de Televisión Nacional de Chile también a su trayectoria; el Premio Municipal de Arte de Santiago; miembro de la Academia Chilena de Bellas Artes; Embajador del Festival Temporales Teatrales de Puerto Montt, entre otros.

Hasta el momento ha escrito aproximadamente veinticinco obras de teatro, habiendo dirigido más de ciento veinte montajes teatrales. El Premio Nacional de Artes de la Representación y Audiovisuales 2007 es un justo reconocimiento a la labor de Gustavo Meza que como hombre de teatro ha batallado por dignificar el teatro de su país y por su lucha ética a favor de la familia teatral - muchos de sus miembros fueron perseguidos, otros desaparecieron y algunos se vieron obligados a exiliarse en el extranjero- en los duros tiempos de la dictadura militar que azotó al país trasandino. El Maestro Meza no sólo es un ejemplar hombre de teatro sino también un gran luchador por la defensa de los derechos humanos de sus colegas.

Victor Bogado

Asunción, Paraguay 